\title{
Pott's puffy tumour in the paediatric population
}

\author{
Taopheeq Bamidele Rabiu
}

Received: 25 February 2010 / Accepted: 19 March 2010 /Published online: 8 April 2010

(C) Springer-Verlag 2010

\section{Dear Editor,}

Whereas it is observed that Pott's puffy tumour is relatively uncommon nowadays compared to the pre-antibiotic era, recent reports in global literature such as that of Tsai et al., constantly serve as reminders to the medical community of the threat posed to the well-being of the paediatric population by the condition, especially if not recognised early [1]. Partial antibiotic treatment for chronic sinusitis, postulated by the authors to be responsible for this resurgence, indicates a need for adults to be more concerned of the care of children and ensures compliance with antibiotic use when indicated.

The literature is replete with reports of this condition in children in whom the frontal sinus is well formed and properly pneumatized reflecting the central role of frontal sinusitis in its pathogenesis. As pointed out by Tsai et al., pneumatisation of the frontal sinus occurs around the age of 6 years and continues into adolescence. Many paediatric reports are therefore in children of 6 years and above $[2,3]$.

A recent report, however, documented its occurrence in the neonatal period [4]. The case was reported at postmenstrual age (PMA) of 32 weeks in a neonate delivered prematurely at PMA of 25 weeks. The authors postulated that haematogenous seeding of infective emboli and retrograde thrombophlebitis might have caused a spread of infection from, for example, orbital cellulitis. Another rare case was reported following an insect bite on the face
[5]. These reports reflect the heterogeneity of the aetiology of the condition.

Operative intervention is often indicated in cases of Pott's puffy tumour. As observed in the series of Tsai et al., the condition may be complicated at presentation by intracranial suppuration. Failure of early recognition of this condition sometimes leads to ineffective treatments. The swelling may subside with the use of antibiotics only for it to recur [5]. This may be due to smouldering infection from bone involvement.

\section{References}

1. Tsai BY, Lin KL, Lin TY, Chiu CH, Lee WJ, Hsia SH, Wu CT, Wang HS (2010) Pott's puffy tumor in children. Childs Nerv Syst 26:53-60

2. Shehu BB, Mahmud MR (2008) Pott's puffy tumor: a case report. Ann Afr Med 7(3):138-140

3. Moser R, Schweintzger G, Uggowitzer M, Urban C, Stammberger H, Eder H, Kerbl R (2009) Recurrent Pott's puffy tumor-atypical presentation of a rare disorder. Wien Klin Wonchenschr 121:719722

4. Cheng S, Vu P (2009) Pott's puffy tumor in a premature neonate: the new youngest case reported in the post-antibiotic Era. Orbit 28 (6):412-414

5. Raja V, Low C, Sastry A, Moriarty B (2007) Pott's puffy tumour following an insect bite. J Postgrad Med 53(2):114-116
T. B. Rabiu $(\bowtie)$

Department of Neurological Surgery, University College Hospital, Ibadan, Nigeria

e-mail: eshohealth@gmail.com 